\title{
Commentary
}

\section{Closing time for CATCH22}

\author{
John Burn
}

At a group meeting in early 1993 to discuss the final draft of our paper on 22q11 deletion in DiGeorge syndrome, I pointed out that the variable clinical features associated with the deletion could be embraced in the acronym CATCH22. ${ }^{1}$ The idea was endorsed by the then editor of the fournal of Medical Genetics and the term became even more prominent when Judith Hall chose it as the title for the associated editorial. ${ }^{2}$ I had presented it by then to the David Smith meeting to general acclaim and it was not until we used it at the UK Clinical Genetics Society that the criticism surfaced that the term carried a negative connotation. In his original book, Heller used the term to describe the challenge whereby insanity was a basis for discharge from air combat but to request discharge was proof of sanity. ${ }^{3}$ The term became more widely used in some countries to denote a "no win" situation. Another criticism of the term, which I recognised almost immediately after it reached print, was that the term "A" referring to "Abnormal facies" was a difficult aspect when counselling. My personal practice was to take CA to mean Cardiac Abnormality and put the "Anomalies of facial development" in parentheses. Subsequently, we qualified the term further and suggested that a more acceptable alternative would be the CATCH phenotype, omitting the " 22 " and with it the negative connotation. ${ }^{4}$

"CATCH phenotype" avoids use of the word "syndrome". In theory this is a neutral term meaning "running together" but it can be taken to have a negative meaning. In particular, trisomy 21 is usually called Down's syndrome in the English speaking world and, given the widespread recognition of the disorder, many people associate "syndrome" with learning disability. The original purpose of the $\mathrm{CATCH}$ acronym was to provide an alternative to the long running debate over eponyms. The name associated in most minds with the disorder was and is DiGeorge, yet the severe neonatal phenotype he first noted ${ }^{5}$ can result from other defects such as $10 \mathrm{p} 13$ and can be a phenocopy owing to maternal diabetes. ${ }^{6}{ }^{7}$ Historically, the Japanese work was contemporary and led to the careful delineation of conotruncal anomaly face syndrome which we showed subsequently to result from deletion of $22 \mathrm{q} 11 .{ }^{8}$ Strong $^{9}$ provided the most complete description including dominant transmission, cardiac involvement in the form of right aortic arch, and late onset

psychosis but the most compelling and widely used alternative name remains velocardiofacial syndrome or VCFS. The associated eponymous title has gained less favour because most people find Bob Shprintzen's name hard to say and even harder to spell!

We suggested that one way of combining these various eponyms and acronyms would be to retain DiGeorge syndrome for the severe neonatal presentation, particularly where there is overt thymic hypoplasia and hypocalcaemia, while VCFS could be used for those children with a predominantly childhood presentation dominated by nasal speech owing to palatal insufficiency. The original work of Takao and his continued active leadership in international cardiovascular development research led us to suggest that Takao syndrome could be an alternative to conotruncal anomaly face (CTAF), where cardiovascular anomalies such as tetralogy of Fallot with major aorticopulmonary collaterals are the most prominent features. All these presentations could then be seen as differing clinical expressions of the CATCH phenotype.

Behind these explanations of why CATCH22 was invented there is, of course, the attraction of conceiving a memorable title, likened recently by Schrander-Stumpel ${ }^{10}$ to playing Scrabble. This is a fair criticism and if the patient groups object then the term CATCH22 cannot be used. We still have the difficulty that simply attaching the name 22 q11 deletion fails to address the common spectrum of phenotypes and the rarer syndromic associations such as Opitz $\mathrm{G} / \mathrm{BBB}^{11}$ and Cayler syndrome. ${ }^{12}$

This review is unlikely to change the preference of those who prefer to equate all 22q11 deletions with DiGeorge syndrome. Despite historical claims, Strong syndrome should not be used and conotruncal anomaly face syndrome would be better called Takao syndrome if it is to be retained at all. Velocardiofacial syndrome or VCFS is now well established and deserves continued widespread recognition as the best term for the typical child with characteristic facial appearance and palatal insufficiency. Many will continue to use $22 \mathrm{q} 11$ deletion syndrome as a satisfactory term $^{13}$ and, given its high frequency, ${ }^{14}$ the consistency of the deleted region involved, and the fact that all the children have "the look" regardless of whether they have other features, this is a defensible position. For those with affection for the acronym, the embracing $\mathrm{CATCH}$ pheno-
Genetics,

19/20 Claremont Place,

Newcastle upon Tyne

NE2 4EE, UK

J Burn 
type should now indicate Cardiac Abnormality, T cell deficit, Clefting, and Hypocalcaemia. Whatever term is used, we must always be sensitive to the need to avoid diminishing the person in our attempts to attach a diagnostic label of any sort.

As the new millennium approaches, it seems an appropriate time to inter CATCH22. What better title for this article than the title of Heller's new book Closing time? ${ }^{15}$

1 Wilson DI, Burn J, Scambler P, Goodship J. DiGeorge syndrome: part of CATCH 22. F Med Genet 1993;30:852-6.

2 Hall JG. CATCH 22. F Med Genet 1993;30:801-2.

2 Hall JG. CATCH 22. F Med Genet 1993;30:801-2.

4 Burn J. Goodship J. Congenital heart disease. In: Rimoin

Burn J, Goodship J. Congenital heart disease. In: Rimoin PL, Connor JM, Pyeritz RE, eds. Emery and Rimoin's principles and practice of medical genetics.

5 DiGeorge AM. Discussions on a new concept of the cellular basis of immunology. $\mathcal{F}$ Pediatr 1996;67:907.
6 Monaco G, Pignata C, Rossi E, Mascellaro O, Cocozza S, Ciccimarra F. DiGeorge anomaly associated with $10 \mathrm{p}$ deleCiccimarra F. DiGeorge anomaly associat
tion. Am 7 Med Genet 1991;39:215-16.

7 Novak RW, Robinson HB. Coincident DiGeorge anomaly and renal agenesis and its relation to maternal diabetes. $A m$ 7 Med Genet. 1994;50:311-12

8 Burn J, Takao A, Wilson D, et al. Conotruncal anomaly face syndrome is associated with a deletion within chromosome 22q11. F Med Genet 1993;30:822-4.

9 Strong WB. Familial syndrome of right-sided aortic arch, mental deficiency, and facial dysmorphism. F Pediatr 1968; 73:882-8.

10 Schrander-Stumpel CT. What's in a name? Am f Med Genet 1998;79:228.

11 McDonald-McGinn DM, Emanuel BS, Zackai EH. Autosomal dominant "Opitz" GBBB syndrome due to a 22q11.2 deletion. Am 7 Med Genet 1996;64:525-6.

12 Giannotti A, Digilio MC, Marino B, Mingarelli R, Dallapiccola B. Cayler cardiofacial syndrome and del22q11: part of the CATCH22 phenotype. Am 7 Med Genet 1994;53: of the

13 Gardner RJM. What's in a name? Am f Med Genet 1999;84:

14 Goodship J, Cross I, LiLing J, Wren C. A population study of chromosome 22q11 deletions in infancy. Arch Dis Child 1998;79:348-51

15 Heller J. Closing time. London: Pocket Books, 1995. 